\title{
The impact of mechanical ventilation systems on acoustic quality in school environments
}

\author{
Fabio Serpilli ${ }^{1 *}$, Samantha Di Loreto ${ }^{1}$, Valter Lori $^{1}$ and Costanzo Di Perna ${ }^{1}$ \\ ${ }^{1}$ Department of Industrial Engineering and Mathematical Sciences, Università politecnica delle \\ Marche,Brecce Bianche 12,60131,Ancona,Italy
}

\begin{abstract}
There is a growing scientific consensus that COVID-19 could be transmitted through the airborne route, putting ventilation at the heart of a mitigation strategy for buildings, including schools. The design of suitable systems requires to consider all aspects both for the control of air movement and the diffusion of bacterial loads, but also of other parameters of indoor air quality. This work examines the acoustic design of ventilation systems in schools and the effects that the systems have on the acoustic quality of the classrooms in compliance with the standard series UNI 11532. The standards provide a guideline on the design and the evaluation of the acoustic performances of schools, including attention for children with special educational needs. In particular, the case study refers to classrooms in the University Politecnica delle Marche, Ancona
\end{abstract}

\section{Introduction}

Several international studies have been conducted to evaluate the performance of the students $[1,2]$ and the factors that most influence it, including classrooms' thermal and acoustic comfort [6-12].

A recent Italian law [29] has established the standard for acoustic comfort for public building. The law deepens the details distinguishing acoustic insulation and acoustic comfort, together with other IAQ indicators, for public buildings. Regarding schools, adequate acoustic comfort targets are required in terms of noise control and acoustic quality. The schools must comply with the Italian standard UNI 11532 Part 1[22], for general requirements and UNI 11532 Part 2 [23] for specific requirements, as reverberation time (RT), Clarity $\left(\mathrm{C}_{50}\right)$ and speech intelligibility (STI).

The most important indoor quality for schools environment is to guarantees adequate speech intelligibility [3-5].

The students who sit in the front rows, next to the professor, can listen better than students who are seated in the farthest rows. In the rear part of large classrooms the teacher's voice becomes weaker and excessive reverberation making listening difficult to them [13].

High background noise level and high reverberation are co-causes of low speech intelligibility in the classroom. The background noise is mainly influenced by the ambient noise levels (outside noise) $[18,19]$, by the student behavior and by noise from internal service equipments.

\footnotetext{
Corresponding author: f.serpilli@univpm.it
} 
The recent global COVID-19 pandemic [16,17] has resulted in a period of lockdown for the entire education sector in Italy, such as in many other countries. The gradual restart planned by the ministry of health and the ministry of education and research provides the management of the teaching spaces with a series of precautions.

In addition, to controlling and limiting of the number of students inside the classrooms, the law also indicates the obligation of adequate ventilation of closed environments. One of the possible solutions to the request of the law is to install ventilation systems in the classrooms $[28,20]$.

The main purpose of classroom ventilation is to create indoor environmental conditions that reduce the risk of health problems among pupils and minimize their discomfort, to eliminate any negative effects on learning [27, 14].

Inadequate classroom ventilation can also reduce the rate at which students carry out lessons and can reduce learning progress [15]. In addition to poor air quality, classrooms often provide unsuitably high temperatures.

Since to move the incoming and outgoing air it is inevitable that these machines have a ventilation system on board, the direct consequence is the presence in the environment of a new source of noise.

A further worsening of the acoustic quality inside the classroom may be caused, in some cases, to the needing of create ventilation ducts connected to the outside air. This causes preferential passages for the noise from the outside to the inside of the building.

The aim of the research was to establish a direct link between the acoustic comfort and cognitive performance of students and the indoor acoustic quality in a classroom and to examine the suitability guidelines on speech intelligibility after the installation of a controlled mechanical ventilation (VMC) system in the classrooms.

\section{Material and methods}

The global COVID-19 pandemic in 2020 introduced new requirements for the ventilation of classrooms. These requirements apply to both new and existing schools. In existing schools, the limits caused by the architecture of the construction sometimes require careful and indepth studies to adapt the systems to the specific case.

The aim of the work is to evaluate the application of the standard UNI 11532-2 [23] to new ventilation systems in existing classroom. In particular, the work aims to analyze whether the method and the reference values can be easily applied also to existing buildings and not only to new school buildings.

The recent standard [22,23], describes the internal acoustical characteristics of confined spaces for the educational sector also giving the design methods and the evaluation techniques.

To meet the obligations of national law, some Italian regions, like the Marche region, have also recently adopted specific regulations to define the installation methods and minimum requirements for ventilation systems in classrooms. These regulations also provide indications about noise immissions of ventilation equipment.

\subsection{Reference value for noise from service equipment}

The Italian references to evaluate the noise produced by equipment installed inside classrooms are the UNI 8199 [21] and UNI 11532 Part 1 and 2 [22,23] standards. In paragraph 4.8 the standard UNI 11532-Part 2 specifies the noise requirements in the school 
environment. The overall noise present in the room, considering it furnished but not occupied by students, is essential for the purposes of:

- A clear understanding of speech in the teacher-pupil relationship.

- A clear understanding of speech among pupils.

As known, the overall noise in a school classroom is caused by:

- Noise sources outside the school (e.g., vehicular traffic, rail traffic, noise from commercial, industrial activities, etc.)

- Noise from continuously operating systems serving the environment (mechanical ventilation systems, heating, cooling, vents, etc.).

Tab. 1 shows the categories of the school environments in relation to their use according to 11532-2 standard.

Table 1. Categories of the school environments in relation to the use

\begin{tabular}{|c|c|c|}
\hline Category & Activity & Interventions \\
\hline$A 1$ & Music & \multirow{5}{*}{$\begin{array}{l}\text { Objective achieved with } \\
\text { integrated design of } \\
\text { geometries, furnishings, } \\
\text { control of residual noise }\end{array}$} \\
\hline$A 2$ & Speech/Conférence rooms & \\
\hline A3 & $\begin{array}{l}\text { Teaching/Speech communication/Convention } \\
\text { rooms/Interaction rooms }\end{array}$ & \\
\hline A4 & $\begin{array}{l}\text { Teaching/Speech communication, Special rooms } \\
\text { included }\end{array}$ & \\
\hline A5 & Sport & \\
\hline A6 & Areas and spaces not intended for learning and libraries & $\begin{array}{l}\text { Objective achieved with } \\
\text { sound absorption and } \\
\text { control of residual noise }\end{array}$ \\
\hline
\end{tabular}

The case study, according to tab.1, takes into consideration A3 category classrooms.

\subsection{Reference value for RT, STI and $\mathrm{C}_{50}$}

According to standard 11532-2 the measurement sessions also include the measurements of RT time, STI and C50.

Reverberation Time T20 and T30 are the values of the reverberation time estimated by the slope of the Schroeder backward-integrated decay, respectively, in the $[\mathrm{dB}]$ ranges: $[-5,-$ 25] for T20 and [-5, -35] for T30 [25].

Clarity C50 is the ratio, in [dB], between the "useful energy" received in the first 50 $[\mathrm{ms}]$ of the impulse response, and the energy received after that. The term "energy" represents the square of the instantaneous values of the pressure impulse response.

The Speech transmission Index (STI) is an objective measure to predict the intelligibility of speech transmitted from talker to listener by a transmission channel. The STI method applies a specific test signal to the transmission channel and by analysing the received test signal; the speech transmission quality of the channel is derived and expressed in a value between 0 and 1, as the Speech Transmission Index (STI). Using the obtained STI-value, the potential speech intelligibility can be determined. STI method is describes in the part 16 of IEC 60268 [24]. 
The reference values of the STI and $\mathrm{C}_{50}$ are described in paragraphs 4.3 and 4.4 of the UNI 11532-2 Standard and refers to a full environment with a maximum of two people present.

$\mathrm{C}_{50}$ can be applied to categories $\mathrm{A} 1, \mathrm{~A} 2, \mathrm{~A} 3$ and $\mathrm{A} 4$ as an alternative to the STI only for classrooms with volume less than $250 \mathrm{~m}^{3}$. For environments with volume $\mathrm{V} \geq 250 \mathrm{~m}^{3}$ only the STI is measured. For both the verification methods to be applied and integrate with the specifications necessary for the case are provided.

The standard in paragraph 4.5 defines the optimal reverberation time $\mathrm{T}_{\text {ott }}$ corresponding to a conventional occupation of the environment equal to $80 \%$ for categories A1, A2, A3 and A4 and to the unoccupied environment for category A5. For categories A1, A2, A3 and A4, if the measurement is performed in a furnished but unoccupied environment, the measured values must be corrected with equation (1) to compare them with the reference limits. The optimal reverberation time $\mathbf{T}_{\mathbf{o t t}}$ in TYPE 1 was calculated in according to the equation (1):

$$
T_{o c c}=\frac{T_{\text {inocc }}}{1+\frac{\Delta A_{\text {pers }} T_{\text {inocc }}}{0,16 V}}
$$

$-T_{\text {occ }}$ : optimal reverberation time for the room occupied at $80 \%$, in seconds.

$-T_{\text {inocc }}$ : optimal reverberation time when the room is not occupied (measurement result), in seconds.

$-V$ : volume of the room, in cubic meters.

$-\Delta A_{\text {pers }}$ : equivalent additional surface area of acoustic absorption of people, in square meters.

The standard refers to the noise due to continuous $\mathrm{L}_{\mathrm{ic} \text {,int }}$ and discontinuous $\mathrm{L}_{\mathrm{id}, \text { int }}$ systems. The methods of verification are indicated in paragraph 6.4 of the UNI 11532-2 standard. The limit values are described in part 4.6 of the same standard. The $\mathrm{L}_{\mathrm{ic}}$, int represents the global noise level of continuous systems in the ambient. It is calculated as the average of the sound pressure levels measured in different user position. The sound pressure level measured for each user position have to be corrected using the background noise correction factor and the reverberation time normalization factor. The $\mathrm{L}_{\mathrm{ic}}$, int noise levels must comply with the values indicated in Tab. 2 below.

The global classroom noise levels, $\mathrm{L}_{\mathrm{amb}}$, must comply with the values shown in paragraph 4.8 of the UNI 11532-2 standard below. Tab. 2 reference values for $\mathrm{L}_{\mathrm{ic}, \text { int }}, \mathrm{L}_{\mathrm{amb}}$ for each destination room.

Table 2. Reference values for the $\mathrm{L}_{\mathrm{ic}, \text { int, }} \mathrm{L}_{\mathrm{amb}}$ levels in the environment

\begin{tabular}{|l|c|c|}
\hline Destination of the room & $\begin{array}{c}\mathbf{L}_{\text {ic,int }} \\
\text { (dBA) }\end{array}$ & $\begin{array}{c}\text { Lamb } \\
(\mathbf{d B A})\end{array}$ \\
\hline Classrooms $<250 \mathrm{~m}^{3}$ & $\leq 34$ & $\leq 38$ \\
\hline Classrooms $\geq 250 \mathrm{~m}^{3}$ & $\leq 38$ & $\leq 41$ \\
\hline Single Office & $\leq 35$ & $\leq 38$ \\
\hline Expositions & $\leq 45$ & $\leq 48$ \\
\hline $\begin{array}{l}\text { Gyms, swimming pools, administrative offices, laboratories, areas open to } \\
\text { the public, canteens, corridors, reception / desk area }\end{array}$ & $\leq 45$ & $\leq 48$ \\
\hline
\end{tabular}

According to the table above, the limit value for the case study are $\mathrm{L}_{\mathrm{amb}} \leq 41 \mathrm{~dB}(\mathrm{~A})$ and $\mathrm{L}_{\mathrm{ic} \text {,int }}$ $\leq 38 \mathrm{~dB}(\mathrm{~A})$. 


\section{The case study}

The noise measurement was carried out in some classrooms of the University of Ancona (Italy). The university building is in a suburban area of the city, away from traffic lines. In addition, the classrooms are located at the rear of the building in relation to the access road; the external ambient noise level during the day-time period is between 40 and $50 \mathrm{~dB}(\mathrm{~A})$. The case study refers to classrooms of the Faculty of Natural Sciences. There are two different kinds of classrooms: without acoustic ceiling (type 1) and with acoustic ceiling (type 2). Below is better described the method applying it to a specific classroom. The rooms have an average height of 3 meters and a base area of about $150 \mathrm{~m}^{2}$. The walls are plastered, the floor is tiled, the ceiling is flat, with double glazed side windows, wooden benches.

Fig. 1 shows the facade of the university to which the classroom are exposed and the arrangement of the desks inside it. These classrooms have a seating capacity of about 150 and are representative of typically university class environments.

A heating, ventilation and air conditioning system was already present in the classrooms when the measurement was taken.

A new mechanical ventilation system (VMC) was recently installed in all the classroom analyzed.
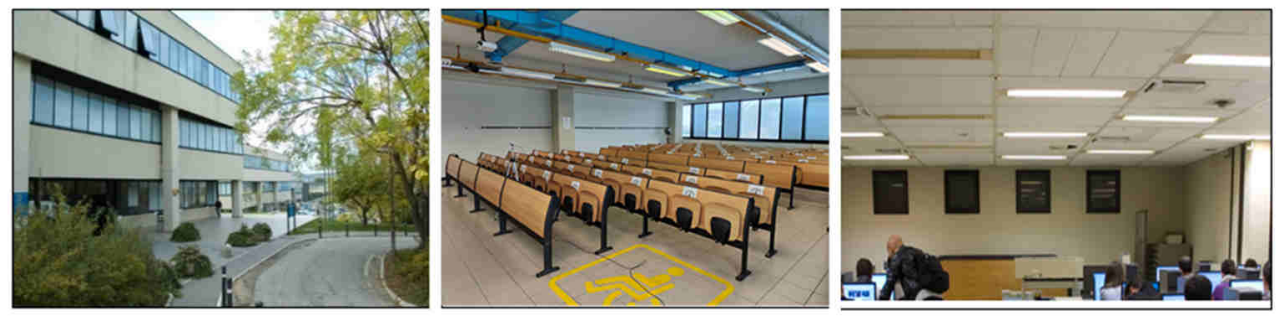

Fig. 1. Photo of University building, and a classroom (type 1 and 2) selected for the study.

The acoustic characterization of the classroom was carried out in compliance with the UNI 11532-1 [22] standard and its referenced standards.

The equivalent sound pressure level of the noise level of technological systems was measured in accordance with UNI EN ISO 16032 [26] in phase - stationary conditions. The acoustic measurements concerned: the equivalent sound pressure level when the mechanical ventilation was off (background noise) and the equivalent sound pressure level in the classroom when the mechanical ventilation was on. The UNI 11532-2 standard requires measurements to be made for at least four different microphone positions.

The measurement of RT time (T30) was performed according to the ISO 3382-2 [25] standard which requires measurements to be made for at least two source positions and three microphone positions.

The measurement of the $\mathrm{C}_{50}$ was performed according to the ISO 3382-2 standard using the impulse response method.

The measurement of the STI was derived from the impulse response measures and background noise measures with the indirect methodology proposed by the EN 60268-16 [24] standard.

For the $\mathrm{C}_{50}$ and STI parameters the UNI 11532 standard requires measurements at least with one source positions and four microphone positions.

All investigations were carried out using the DIRAC Room Acoustic software, combined with the Edirol FA-101 external firewire soundcard. The sound field for intelligibility measurements was excited using a directional sound source, in compliance with 
11532, consisting of a speaker with a diameter of $100 \mathrm{~mm}$, powered by an MLS signal. The measurements of the RT time were carried out using a dodecahedral source, fed with a linesweep signal. The acquisition of impulse responses was achieved by taking the output signal of a B\&K 2250 sound level meter. Considering that the VMC can operate at different speeds, the measurements were repeated in all operating conditions.

The ventilation systems installed in the classrooms are of the same type, but of different sizes depending on the air volumes required in each classroom. In all the classrooms were installed two RTD system. It is possible to set the air flow in two configurations: $950 \mathrm{~m}^{3} / \mathrm{h}$ and $1200 \mathrm{~m}^{3} / \mathrm{h}$ (respectively minimum and maximum performance) for both.

The Sound power level declared in the technical specifications of the RTD is $\mathrm{L}_{w}=78,1$ $\mathrm{dB}$ (A). The unit carries out the exchange and treatment of the air and is equipped with high efficiency thermodynamic recovery. The recovery is carried out by means of an integrated refrigerant circuit operating as a heat pump. The unit operates with two air flows, a fresh air flow coming from outside the building and an expulsion air flow coming from inside the building. The unit is designed for the extraction and renewal of air in environments that are generally already equipped with their own air conditioning systems. Both fans, both for the external air flow and for the expulsion air flow, are plug-fans with backward blades driven by electronically controlled brushless DC motors. The unit control of ventilation keeps the air flow rate of the renewal flow constant.

The description and the installation scheme are in the following fig. 2 .
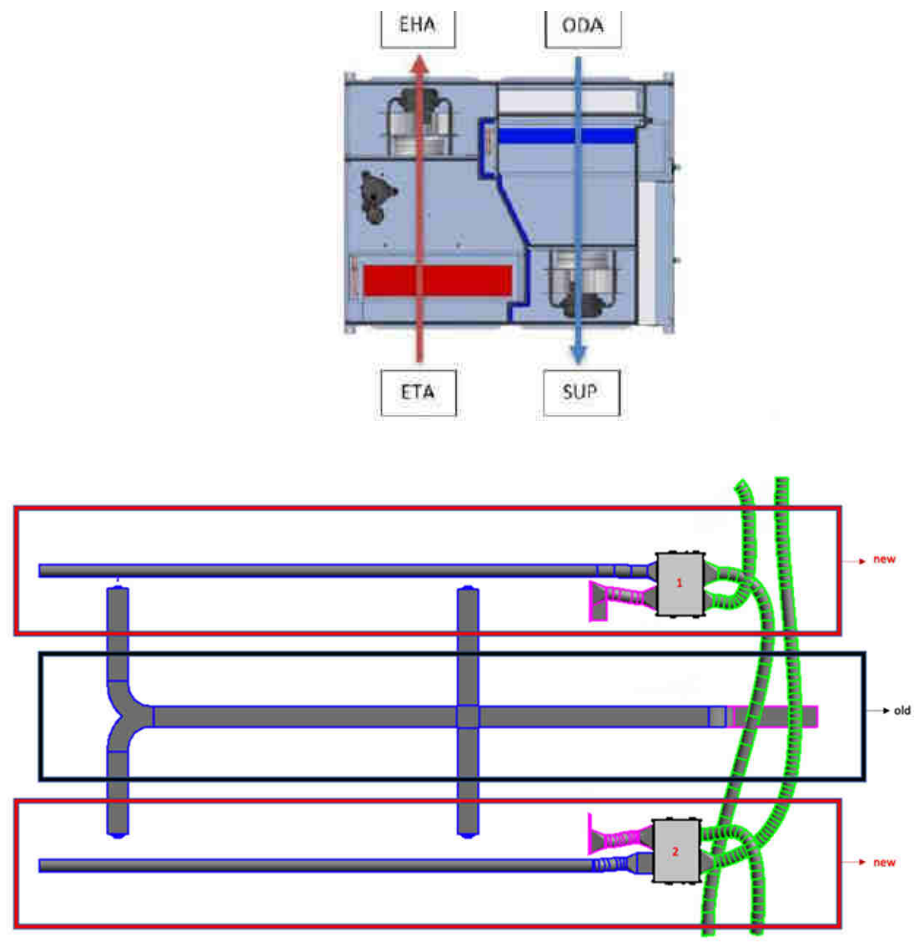

Fig. 2. Installation scheme that shows the old (circled in blue) and the new (circled in red) system both. 
During the period of the measures described in this work, the lockdown imposed by the Ministry of Health was still in force. For this reason, no students were present in the faculty. Furthermore, no cars passed near the classrooms. The contribution of external noise in this situation was therefore considered negligible for the purposes of the assessments described below.

\section{Acoustic measurements}

In the selected classroom, measurements of the equivalent sound pressure level of the noise of the new systems were carried out in accordance with the UNI 11532 standard. Measurements of the intelligibility indicators, C50 and STI, were also carried out, in addition to background noise and reverberation time.

The measurements in the classroom were made in four measurement points, chosen in compliance with 11532-2 (Fig. 3). In particular, three positions were selected along the longitudinal axis of the classroom and a position representative of the most unfavorable condition in terms of distance from the speaker and proximity to the noise produced by the ventilation system. Fig. 4 shows the floor plan of the classroom TYPE 1, the measurement points numbered and circled in blue, and the position of the source drawn in red.
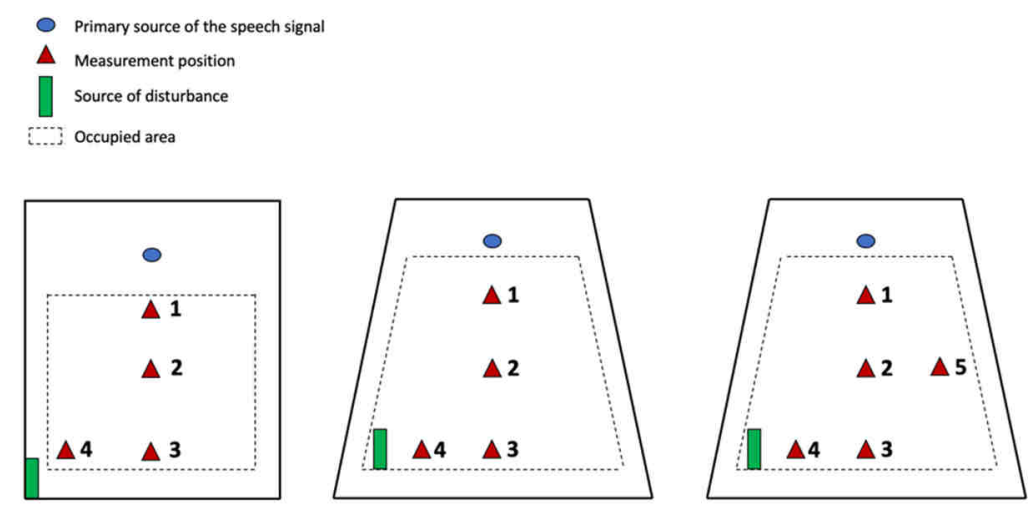

Fig. 3. Measurements points and source position according to UNI 11532 Part 2.

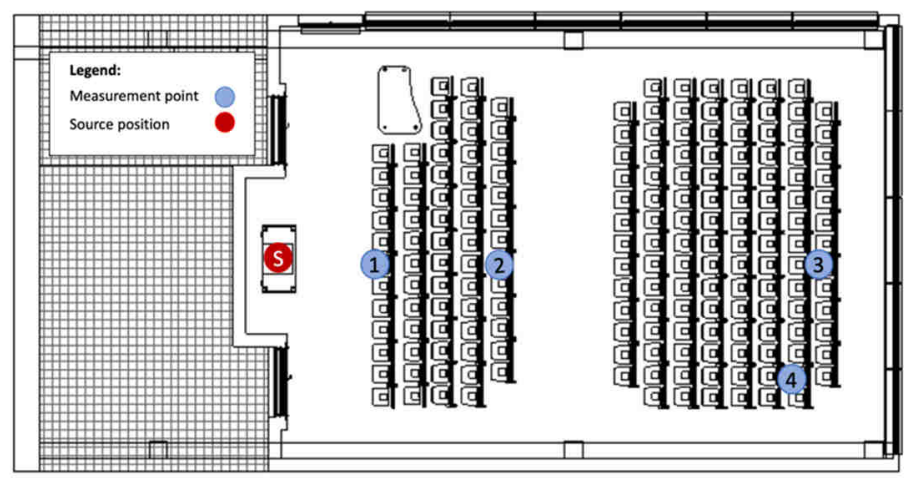

Fig. 4. Floor plan of the class type 1, measurement points and source position. 
Due to the configuration of the ventilation system, in addition to the measurement points imposed by the legislation, it was decided to select three points below the supply and return ducts.

This choice was dictated by the need to understand which was the loudest listening point in terms of distribution of system in the classroom.

Tables 3 to 7 report the results of measurement session in classrooms.

Table 3. Results of RT measurements by octave bands.

\begin{tabular}{|c|c|c|}
\hline \multirow{2}{*}{ Frequency [Hz] } & RT- full classroom [s] & RT- full classroom [s] \\
\cline { 2 - 3 } & Type 1 & Type 2 \\
\hline 125 & 1,48 & 0,61 \\
\hline 250 & 0,97 & 0,54 \\
\hline 500 & 0,82 & 0,51 \\
\hline 1000 & 0,80 & 0,53 \\
\hline 2000 & 0,71 & 0,51 \\
\hline 4000 & 0,67 & 0,42 \\
\hline
\end{tabular}

Table 4. Results of STI for single point of measure, STI mean and STI mean with measurement uncertainty. Classroom type 1.

\begin{tabular}{|c|c|c|c|c|c|c|}
\hline \multicolumn{7}{|c|}{ Ventilation OFF } \\
\hline STI,p1 & STI,p2 & STI,p3 & STI,p4 & $\underset{\text { mean }}{\text { STI }}$ & $\begin{array}{c}\text { STI mean with } \\
\text { measurement } \\
\text { uncertainty }\end{array}$ & $\begin{array}{l}\text { Speech quality in } \\
\text { accordance with } \\
\text { CEI EN 60268-16 }\end{array}$ \\
\hline 0,59 & 0,5 & 0,45 & 0,48 & 0,51 & 0,46 & FAIR \\
\hline \multicolumn{7}{|c|}{ Ventilation $950 \mathrm{~m}^{3} / \mathrm{h}$} \\
\hline STI,p1 & STI,p2 & STI,p3 & STI,p4 & $\underset{\text { mean }}{\text { STI }}$ & $\begin{array}{c}\text { STI mean with } \\
\text { measurement } \\
\text { uncertainty }\end{array}$ & $\begin{array}{l}\text { Speech quality in } \\
\text { accordance with } \\
\text { CEI EN 60268-16 }\end{array}$ \\
\hline 0,38 & 0,29 & 0,25 & 0,29 & 0,30 & 0,25 & $\mathrm{BAD}$ \\
\hline \multicolumn{7}{|c|}{ Ventilation $1200 \mathrm{~m}^{3} / \mathrm{h}$} \\
\hline STI,p1 & STI,p2 & STI,p3 & STI,p4 & $\underset{\text { mean }}{\text { STI }}$ & $\begin{array}{c}\text { STI mean with } \\
\text { measurement } \\
\text { uncertainty }\end{array}$ & $\begin{array}{l}\text { Speech quality in } \\
\text { accordance with } \\
\text { CEI EN 60268-16 }\end{array}$ \\
\hline 0,35 & 0,28 & 0,26 & 0,27 & 0,29 & 0,24 & $\mathrm{BAD}$ \\
\hline
\end{tabular}


Table 5. Results of STI for single point of measure, STI mean and STI mean with measurement uncertainty. Classroom type 2.

\begin{tabular}{|c|c|c|c|c|c|c|}
\hline \multicolumn{7}{|c|}{ Ventilation OFF } \\
\hline STI,p1 & STI,p2 & STI,p3 & STI,p4 & $\begin{array}{c}\text { STI } \\
\text { mean }\end{array}$ & $\begin{array}{c}\text { STI mean with } \\
\text { measurement } \\
\text { uncertainty }\end{array}$ & $\begin{array}{l}\text { Speech quality in } \\
\text { accordance with } \\
\text { CEI EN 60268-16 }\end{array}$ \\
\hline 0,89 & 0,81 & 0,75 & 0,48 & 0,78 & 0,77 & EXCELLENT \\
\hline \multicolumn{7}{|c|}{ Ventilation $900 \mathrm{~m}^{3} / \mathrm{h}$} \\
\hline STI,p1 & STI,p2 & STI,p3 & STI,p4 & $\begin{array}{c}\text { STI } \\
\text { mean }\end{array}$ & $\begin{array}{c}\text { STI mean with } \\
\text { measurement } \\
\text { uncertainty }\end{array}$ & $\begin{array}{l}\text { Speech quality in } \\
\text { accordance with } \\
\text { CEI EN 60268-16 }\end{array}$ \\
\hline 0,68 & 0,69 & 0,65 & 0,68 & 0,67 & 0,64 & GOOD \\
\hline
\end{tabular}

The degree of intelligibility in accordance with the standard has been assigned considering the results of the corrected STI with uncertainty.

Table 6. Results of $\mathrm{Lic}_{\mathrm{ic}}$, int $\mathrm{dB}$ (A) for two conditions of Ventilation.

\begin{tabular}{|c|c|c|c|}
\hline Type of room & $\begin{array}{c}\mathbf{L}_{\mathrm{ic}, \text { int }} \mathbf{d B}(\mathrm{A}) \\
{\left[\boldsymbol{V M C} \mathbf{M 5 0} \mathbf{m}^{\mathbf{3}} / \boldsymbol{h}\right]}\end{array}$ & $\begin{array}{c}\mathbf{L}_{\mathrm{ic}, \text { int }} \mathbf{d B}(\mathrm{A}) \\
{\left[\boldsymbol{V M C} \mathbf{1 2 0 0 \mathbf { m } ^ { 3 }} / \boldsymbol{h}\right]}\end{array}$ & $\begin{array}{c}\mathbf{L}_{\mathrm{ic}, \text { int }} \mathbf{d B}(\mathrm{A}) \\
\text { [reference value] }\end{array}$ \\
\hline Type 1 & 44,6 & 45,5 & $<38 \mathrm{~dB}(\mathrm{~A})$ \\
\hline
\end{tabular}

\begin{tabular}{|c|c|c|}
\hline Type of room & $\begin{array}{c}\mathbf{L}_{\mathbf{i c}, \text { int }} \mathbf{d B}(\mathrm{A}) \\
{\left[\boldsymbol{V M C} \mathbf{9 0 0 \boldsymbol { m } ^ { 3 }} / \boldsymbol{h}\right]}\end{array}$ & $\begin{array}{l}\mathbf{L}_{\mathbf{i c}, \text { int }} \mathbf{d B}(\mathrm{A}) \\
\text { [reference value] }\end{array}$ \\
\hline Type 2 & 37,8 & $<38 \mathrm{~dB}(\mathrm{~A})$ \\
\hline
\end{tabular}

Table 7. Results of $\mathrm{L}_{\mathrm{amb}} \mathrm{dB}$ (A) for two conditions of Ventilation.

\begin{tabular}{|c|c|c|c|}
\hline Type of room & $\begin{array}{c}\mathrm{L}_{\text {amb }} \mathrm{dB}(\mathrm{A}) \\
{\left[V M C 950 \mathrm{~m}^{3} / \mathrm{h}\right]}\end{array}$ & $\begin{array}{c}\mathrm{L}_{\mathrm{amb}} \mathrm{dB}(\mathrm{A}) \\
{\left[V M C 1200 \mathrm{~m}^{3} / \mathrm{h}\right]}\end{array}$ & $\begin{array}{l}\mathrm{L}_{\mathrm{amb}} \mathrm{dB}(\mathrm{A}) \\
\text { [reference value] }\end{array}$ \\
\hline Type 1 & 48,6 & 49,5 & $<41 \mathrm{~dB}(\mathrm{~A})$ \\
\hline
\end{tabular}

\begin{tabular}{|c|c|c|}
\hline Type of room & $\begin{array}{c}\mathbf{L}_{\text {ic, int }} \mathbf{d B}(\mathrm{A}) \\
{\left[\mathbf{V M C ~}_{\mathbf{M}} \mathbf{9 0 0 \mathbf { m } ^ { 3 }} / \boldsymbol{h} \text { ] }\right.}\end{array}$ & $\begin{array}{c}\mathbf{L}_{\text {amb }} \mathbf{d B}(\mathrm{A}) \\
\text { [reference value] }\end{array}$ \\
\hline Type 2 & 40,7 & $<41 \mathrm{~dB}(\mathrm{~A})$ \\
\hline
\end{tabular}




\section{Conclusions}

The aim of the study was to analyzed the relation between the acoustic comfort and the indoor air quality in a sample of classrooms of the University Politecnica delle Marche (Ancona) after the installation of controlled mechanical ventilation systems. The case study analyzed has highlighted how the new systems of HVAC can negatively affect the acoustic quality of a classroom, when it doesn't have an internal acoustic treatment. The acoustic quality of the classrooms was investigated in accordance with the UNI 11532-2 Italian standard.

In the classrooms that do not have any acoustic treatments, the internal acoustic quality is poor and does not comply with the reference values given by UNI 11532-2 standard. The RT values measured at $1000 \mathrm{~Hz}$ are over $0.7 \mathrm{~s}$. The STI values measured are less than 0,5 even with the VMC sources turned off. The ambient noise level measured are higher than 41 $\mathrm{dB}(\mathrm{A})$ with the VMC sources turned off. It means that the classrooms need significant acoustic corrections.

The VMC sources get worse the internal acoustic quality especially in term of speech intelligibility and ambient noise levels, with negative consequences for both the teacher and the student. The global noise level of continuous systems measured, $\mathrm{L}_{\mathrm{ic}}$, int, with the VMC sources turned on, are higher than $45 \mathrm{~dB}(\mathrm{~A})$ and the STI values decrease significantly even in the position near the speaker.

In the classrooms with acoustic treatments and with RT values that comply the UNI 11532-2 there are not any problems if a new ventilation system is installed. In this type of classroom, if the ventilation system is activated, the STI values deteriorate a little but still remain good.

The study does not consider another important and potential negative effect of the installation of the VMC system that have to be carefully taken into account. Ventilation systems for their operation require a connection through air ducts to the outside. If these ducts are not silenced, they can become a preferential route for the passage of external environmental noise. This can determine high ambient noise level due to the connections of the classrooms with the common areas and with the outside environment.

Future developments of the work will be directed towards the optimization of the considered acoustic parameters, so that with optimization techniques, the arrangement of the mechanical ventilation systems, that allows the best acoustic comfort, can be chosen in an appropriate manner. In addition, more acoustically performing VMC systems could be used to reduce the ambient noise in the classrooms. To improve the speech intelligibility, it is also necessary to proceed to an accurate design of the electroacoustic systems that consider the dimensions and the geometries of the environments.

\section{References}

1. Kamaruzzaman, S.; Sabrani, N. The effect of indoor air quality (IAQ) towards occupants' psychological performance in office buildings. J. Des. Built 2011, 4, 4961.

2. Haverinen-Shaughnessy, U.; Shaughnessy, R.J.; Cole, E.C.; Toyinbo, O.; Moschandreas, D.J. An assessment of indoor environmental quality in schools and its association with health and performance. Build. Environ. 2015, 93, 35-40.

3. Shield, B.M.; Dockrell, J.E. The effects of environmental and classroom noise on the academic attainments of primary school children. J. Acoust. Soc. Am. 2008, $123,133-144$. 
4. Calosso, G.; Puglisi, G.E.; Astolfi, A.; Castellana, A.; Carullo, A.; Pellerey, F. A one-school year longitudinal study of secondary school teachers' voice parameters and the influence of classroom acoustics. J. Acoust. Soc. Am. 2017, 142, 10551066 .

5. Crandell, C.C.; Smaldino, J.J. Classroom acoustics for children with normal hearing and with hearing impairment. Lang. Speech. Hear. Serv. Sch. 2000, 31, 362-370.

6. P. Wargocki, D.P. Wyon, The effects of moderately raised classroom temperatures and classroom ventilation rate on the performance of schoolwork by children (RP1257), HVAC\&R Res. 13 (2) (2007) 193-220.

7. Z. Bakó-Biró, D.J. Clements-Croome, N. Kochhar, H.B. Awbi, M.J. Williams,Ventilation rates in schools and pupils' performance, Build. Environ. 48 (2012)215-223.

8. I. Sarbu, C. Pacurar, Experimental and numerical research to assess indoor environment quality and schoolwork performance in university classrooms, Build. Environ. 93 (2015) 141-154.

9. J. Toftum, B.U. Kjeldsen, P. Wargocki, H.R. Menå, E.M.N. Hansen, G. Clausen, Association between classroom ventilation mode and learning outcome in Danish schools, Build. Environ. 92 (2015) 494-503.

10. Serpilli, Lori, Di Loreto, Speech recognition assessment in Italian pediatric schools using closest speech tests: a case of study, Internoise Conference 2020, Seoul.

11. Buchari, and Nazaruddin Matondang, The impact of noise level on students' learning performance at state elementary school in Medan, AIP Conference 2017, Zurich.

12. Word Health Organization, WHO Timeline - COVID-19. https://www.who.int/news/item/27-04-2020-who-timeline--Covid-19.

13. C. VM Vouriot, H. Burridge, J. Noakes, P.F.Linden, Seasonal variation in airborne infection risk in schools due to changes in ventilation inferred from monitored carbon dioxide, International Journal of Indoor Environment and Health, 00:1-10, 2021.

14. Jie Gao, Pawel Wargocki, Yi Wang,Ventilation system type, classroom environmental quality and pupils' perceptions and symptoms, Building and Environment, Volume 75,2014,Pages 46-57.

15. A. Astolfi, L.Parati, D. D'Orazio, M.Garai, The new italian standard UNI 11532 on acoustics for school, ICA 2019 AACHEN.

16. Schaffer ME, A pratical Guide to noise and Vibration control for HVAC system (SI), $2^{\text {nd }}$ ed, ASHRAE, 2011.

17. Pawel Wargocki, David P. Wyon, Providing better thermal and air quality conditions in school classrooms would be cost-effective, Building and Environment, Volume 59, 2013, Pages 581-589.

18. Kristiansen, J.; Persson, R.; Lund, S.P.; Shibuya, H.; Nielsen, P.M. Effects of classroom acoustics and self-reported noise exposure on teachers' well-being. Environ. Behav. 2013, 45, 283-300.

19. Puglisi, G.E.; Astolfi, A.; Cantor Cutiva, L.; Carullo, A. Assessment of indoor ambient noise level in school classrooms. In Proceedings of the Conference on Noise Control-EuroNoise, Maastricht, The Netherlands, 31 May-3 June 2015.

20. Park, S.; Choi, Y.; Song, D.; Kim, E.K. Natural ventilation strategy and related issues to prevent coronavirus disease 2019 (COVID-19) airborne transmission in a school building. Sci. Total Environ. 2021, 789, 147764.

21. Standard UNI 8199 - Acustica in edilizia - Collaudo acustico di impianti a servizio di unità immobiliari - Linee guida contrattuali e modalità di misurazione all'interno degli ambienti serviti, 2016. 
22. Standard UNI 11532-1. Caratteristiche acustiche interne di ambienti confinati Metodi di progettazione e tecniche di valutazione - Parte 1: Requisiti generali, 2018

23. Standard UNI 11532-2. Caratteristiche acustiche interne di ambienti confinati Metodi di progettazione e tecniche di valutazione - Parte 2: Settore scolastico, 2020.

24. CEI EN 60268-16. Sound system equipment part 16: Objective rating of speech intelligibility by speech transmission index, 2012.

25. Standard UNI EN ISO 3382-2 - Acustica - Misurazione dei parametri acustici degli ambienti - Parte 2: Tempo di riverberazione negli ambienti ordinari, 2008.

26. Standard UNI EN ISO 16032 - Acustica - Misurazione del livello di pressione sonora di impianti tecnici in edifici - Metodo tecnico progettuale, 2005.

27. ASHRAE. ANSI/ASHRAE Standard 62.1-2016 Ventilation for Acceptable Indoor Air Quality; ASHRAE: Atlanta, GA, USA, 2016. k

28. ASHRAE. ANSI/ASHRAE Standard 62.2-2016 Ventilation for Acceptable Indoor Air Quality in Residential Buildings; ASHRAE: Atlanta, GA, USA, 2016. I

29. DECRETO 11 ottobre 2017 Criteri ambientali minimi per l'affidamento di servizi di progettazione e lavori per la nuova costruzione, ristrutturazione e manutenzione di edifici pubblici. (17A07439) (GU Serie Generale n.259 del 06-11-2017) 